\title{
The correlation of social support with mental health: A meta-analysis
}

Tayebeh Fasihi Harandi ${ }^{1}$, Maryam Mohammad Taghinasab ${ }^{2}$, Tayebeh Dehghan Nayeri ${ }^{3}$

${ }^{1}$ Ph.D. Of Health Education and Health Promotion, Assistant Professor, Social Determinants of Health Research Center, Alborz University of Medical Sciences, Karaj, Iran

${ }^{2}$ M.Sc. of Assessment and Measurement, Allame Tabataba'i University. Tehran. Iran

${ }^{3}$ Ph.D. Student in Assessment and Measurement, Allame Tabataba'i University. Tehran. Iran

Type of article: Meta-analysis

\begin{abstract}
Background and aim: Social support is an important factor that can affect mental health. In recent decades, many studies have been done on the impact of social support on mental health. The purpose of the present study is to investigate the effect size of the relationship between social support and mental health in studies in Iran.

Methods: This meta-analysis was carried out in studies that were performed from 1996 through 2015. Databases included SID and Magiran, the comprehensive portal of human sciences, Noor specialized magazine databases, IRANDOC, Proquest, PubMed, Scopus, ERIC, Iranmedex and Google Scholar. The keywords used to search these websites included "mental health or general health," and "Iran" and "social support." In total, 64 studies had inclusion criteria meta-analysis. In order to collect data used from a meta-analysis worksheet that was made by the researcher and for data analysis software, CMA-2 was used.

Results: The mean of effect size of the 64 studies in the fixed-effect model and random-effect model was obtained respectively as 0.356 and 0.330 , which indicated the moderate effect size of social support on mental health. The studies did not have publication bias, and enjoyed a heterogeneous effect size. The target population and social support questionnaire were moderator variables, but sex, sampling method, and mental health questionnaire were not moderator variables.

Conclusion: Regarding relatively high effect size of the correlation between social support and mental health, it is necessary to predispose higher social support, especially for women, the elderly, patients, workers, and students.
\end{abstract}

Keywords: Social support, Mental health, Meta-analysis, General health

\section{Introduction}

The World Health Organization defines mental health as a state of well-being, that in which the individual knows their capabilities and uses them effectively and productively that will be useful for their respective communities (1). Considering that health is a concept influenced by a set of complex factors, i.e. biological, psychological, social, cultural, economic and spiritual, it should be acknowledged that health and mental illness do not simply have biological or psychological aspects, but also have concurrent social dimensions and nature. Social factors, which can play an important role in creating, maintaining, and promoting health, have been a major role in incidence, prevalence and persistence of the disease (2). In this respect, it is very important to pay attention to social factors influencing mental health, and perceived social support is one of those factors. Social support represents the amount of support that a person perceives and reports receive it. Social support is a phenomenon that involves interactions of people so that when a person offers social interaction, it has an important role in his health (3). Social support alone is not important, but what is important is the belief in the existence of social support (4). Social support provides physical and psychological advantages for people faced with stressful physical and psychosocial events, and is considered as a factor reducing the psychological distress when faced with stressful events (5). Numerous studies

\section{Corresponding author:}

Assistant Professor Dr. Tayebeh Fasihi Harandi, Social Determinants of Health Research Center, Alborz University of Medical Sciences, Karaj, Iran. Tel: +98.9022002806, Email: tfasihih@ gmail.com

Received: October 09, 2016, Accepted: June 04, 2017, Published: September 2017

iThenticate screening: May 31, 2017, English editing: June 26, 2017, Quality control: July 12, 2017

(C) 2017 The Authors. This is an open access article under the terms of the Creative Commons Attribution-NonCommercialNoDerivs License, which permits use and distribution in any medium, provided the original work is properly cited, the use is non-commercial and no modifications or adaptations are made. 
have been performed on the effect of social support on health, quality of life, and especially mental health over the recent decades. However, each study has been performed on a different population, and has used different instruments, sampling methods and statistical populations, which have resulted in different results. For instance (68) found a strong correlation between social support and mental health, and (9-11) found a weak correlation in this regard. Hence, in the face of much varied and sometimes contradictory scientific information for quick and precise extraction of information, it is necessary that resources be extracted systematically and results be integrated to achieve a tangible and overall result. This helps to minimize bias in these studies, and also reduce errors (12). In meta-analysis, the aim is not only to summarize the literature to an average effect size, but to try to determine the factors that affect the size effects (13). The approach allows the researcher to determine the features specific to the previous studies and factors making the effect sizes of the studies different, and to make conclusions about the correlations between variables more decisively (12). In total, 41 studies were collected to perform a meta-analysis on the effect of social support on physical health. The results of their analysis showed the correlation of social support with the failure to practice health and the increased mortality in the range of -0.60 to +0.23 (14). A 2005 study by De Silva in a systematic review, examined 21 research studies that had been done on the relationship between social capital and mental health (15). Another study examined correlation of 16 health outcome variables, including health status, physical symptoms, psychological symptoms, depression, role performance, behavior, physical compatibility, psychological adjustment, living adaptability, coping behaviors, stress, health belief, health promoting behaviors, quality of life, well-being, and self-actualization with social support. Results showed that social support can significantly predict all health outcomes, except physical compatibility, at the level of (0.0001) (16). (In a meta-analysis, 122 research studies on relationship between structural or functional social support with patient adherence to medical regimens were examined (17). Results showed that significant effect size of research variables on patient adherence and the content and methodology variables influenced the size effect (17). A metaanalysis in this regard was performed in Iran (18). However, they reviewed only 8 studies, which is not a good representative for available research community, and did not examine the moderator variables, such as sex, measurement instruments, and sampling methods. Therefore, this study was conducted to review the previous studies, combine the results, and assess those studies more comprehensively and accurately, taking into account the moderator variables relevant to the effect size of correlation of social support on mental health in the Iranian population.

\section{Material and Methods}

\subsection{Research design and search strategy}

In this systematic review, the correlation of social support and mental health was examined through meta-analysis. The statistical population of this study included all published and unpublished articles, studies, and dissertations performed from 1996 through 2015 on the correlation of social support with mental health in Iran. To collect the relevant studies, initial searches were carried out in Iranian databases, including the Iranian Research Institute for Information Science and Technology (IRANDOC), Scientific Information Database (SID) and Magiran, Comprehensive Portal of Human Sciences, Noor specialized magazine, and Google Scholar databases, to find Iranian articles and theses published in Farsi; and then in foreign databases, including Proquest, PubMed, Scopus, ERIC, Iranmedex, and also, Google Scholar, advance searches were carried out to find Iranian articles that were published in English in the relevant area. The keywords used to search the above websites included "mental health or general health," "Iran," and "social support."

\subsection{Inclusion and exclusion criteria}

The inclusion criteria in the meta-analysis were as follows: a) studies should be performed on the correlation of social support with mental health, b) the theses should be related to the M.Sc. or Ph.D. degree (available in IRANDOC), c) the method should be experimental, quasi-experimental, post-event, or co relational, and d) all studies should be performed during the years 1996 through 2015. Exclusion criteria included: a) failure to investigate the relationship between social support and mental health, b) absence of full-text of article c) failure to report statistics to calculate effect sizes, d) descriptive study or review. Retrieval and selection process of studies is shown in the Figure 1.

\subsection{Quality assessment and data analysis}

In the next step, the data related to those 64 studies were encoded and then recorded in the worksheet of the metaanalysis. The worksheet was specifically designed by the researcher to record the required data of the meta-analysis. The worksheet included the title of the study, authors' details, university name, website information, the year and place of the study, the study variables, research questions and hypotheses, sex of the samples, the statistical 
population, sample size, occupation, educational level, province, mental health instrument, type of support, the study design, statistical tests, significance level, and the effect size. The Comprehensive Meta-analysis software (CMA-2) was used to analyze the collected data. In the data analysis, the correlation coefficient was calculated as the estimator of the effect size in each study. The Hunter-Schmidt meta-analysis approach was used to calculate the combined effect size (the combined effect size of the variables in both fixed-effect and random-effect model). The Egger's regression intercept, classic fail-safe $\mathrm{N}$ test, Duval and Tweedie's trim and fill, and funnel plot were used to examine the publication bias. The Q and 12 tests were used to analyze the homogeneity of the studies.

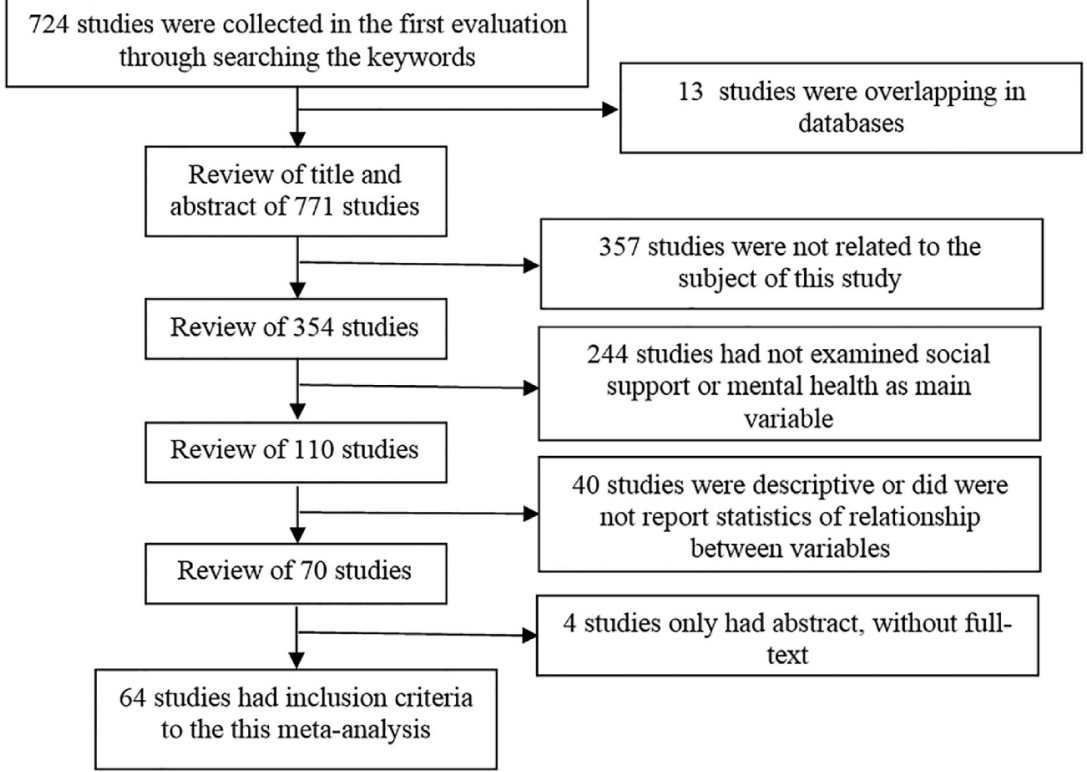

Figure1. Retrieval and selection process of studies

\section{Results}

In this study, 64 studies (13 theses and 51 articles) were collected and analyzed. About $36 \%$ of the studies had been performed in Tehran, Iran. Most of the studies (77\%) had been performed both on men and women, and most of the studies (almost 90\%) had been performed from 2006 through 2013 (Table 1). The target population of one third of the studies was initially, university students and then workers (including employees, nurses, \& teachers). The studies performed on the older adults and patients comprised $14 \%$ and $11 \%$, respectively. About $60 \%$ of the studies had used GHQ-28 to measure mental health, and 20\% of the studies had used GHQ-12. The most popular questionnaire used to measure social support in the studies was Zimet's questionnaire and then Philip's and Stanford's questionnaires. Almost one third of the studies had used cluster sampling method to select samples. The mean of effect size of 64 studies was obtained as 0.356 , based on the fixed-effect model and 0.330 , based on the randomeffect model, which was higher than the average level in the standards presented by Cohen (19), and indicated the effectiveness of social support in mental health in the Iranian population. The results of Egger's regression $(\mathrm{t}=1.505$ $\& \mathrm{p}>0.05$ ) showed that the intercept of the regression line in the studies was almost zero, which implies no publication bias in the studies. According to the results of the classic fail-safe N test, 4,524 studies with mean effect size of zero should be entered to effect size could be cancelled, which showed the reliability of the total effect size. Based on Duval and Tweedie's trim and fill and funnel plot, in the fixed and random-effect model, 13 and 11 studies respectively should be added to the right side to make the funnel plot symmetric (Figure 2). The Q statistic was used to examine the heterogeneity of the studies. The Q statistic was obtained as 941.320 for the studies, and it could be concluded that the studies were heterogeneous $(\mathrm{p} \leq 0.001)$. Furthermore, I2 showed that $93.307 \%$ of variations in all the studies were due to the heterogeneity of the studies. In this respect, the sex, target population, sampling method, and instruments for measurement of social support and mental health were examined as moderator variables (Table 2). 
Table 1. Descriptive characteristics of the collected studies and their size effect

\begin{tabular}{|c|c|c|c|c|c|c|c|c|}
\hline $\begin{array}{l}\text { Ref. } \\
\text { no. }\end{array}$ & Gender & Target population & $\mathrm{n}$ & $\begin{array}{l}\text { Sampling } \\
\text { Method }\end{array}$ & $\begin{array}{l}\text { General } \\
\text { health }\end{array}$ & $\begin{array}{l}\begin{array}{l}\text { Social } \\
\text { support }\end{array} \\
\end{array}$ & $\begin{array}{l}\text { Effect } \\
\text { size }\end{array}$ & $\begin{array}{l}\mathrm{p}- \\
\text { value }\end{array}$ \\
\hline 20 & $M \& F$ & Student college & 3261 & Census & GHQ-12 & Sarason & 0.620 & 0.0001 \\
\hline 21 & $\mathrm{M} \& \mathrm{~F}$ & Elder & 312 & Stratified & GHQ-12 & Unknown & 0.243 & 0.0001 \\
\hline 22 & $\mathrm{M} \& \mathrm{~F}$ & Elder & 200 & Cluster & GHQ-12 & Rook -Ituarte & 0.333 & 0.0001 \\
\hline 23 & $\mathrm{M} \& \mathrm{~F}$ & Employee & 300 & Stratified & GHQ-28 & Social Capital & 0.660 & 0.0001 \\
\hline 24 & $\mathrm{M} \& \mathrm{~F}$ & Student college & 136 & Stratified & GHQ-28 & Philips & 0.326 & 0.0001 \\
\hline 25 & $\mathrm{M} \& \mathrm{~F}$ & Student college & 400 & Stratified & SCL-25 & Zimet & 0.209 & 0.0001 \\
\hline 26 & $\mathrm{M} \& \mathrm{~F}$ & Student & 200 & Census & GHQ-28 & Researcher & 0.219 & 0.002 \\
\hline 27 & $\mathrm{M} \& \mathrm{~F}$ & Student college & 102 & Census & GHQ-12 & Zimet & 0.175 & 0.079 \\
\hline 9 & $M \& F$ & Elder & 284 & Cluster & GHQ-28 & Researcher & 0.050 & 0.404 \\
\hline 28 & $M \& F$ & Employee & 320 & Cluster & GHQ-28 & Katrona & 0.323 & 0.0001 \\
\hline 29 & $\mathrm{~F}$ & Abused women & 114 & Convenience & GHQ-12 & Stanford & 0.390 & 0.0001 \\
\hline 8 & $\mathrm{M}$ & Elder & 84 & Convenience & GHQ-12 & Philips & 0.677 & 0.0001 \\
\hline 30 & $\mathrm{M} \& \mathrm{~F}$ & Employee & 300 & Cluster & GHQ-12 & Social Capital & 0.121 & 036.0 \\
\hline 31 & $\mathrm{M} \& \mathrm{~F}$ & Elder & 320 & Cluster & GHQ-12 & Social Capital & 0.197 & 0.0001 \\
\hline 32 & $\mathrm{M} \& \mathrm{~F}$ & Student college & 297 & Simple Random & GHQ-28 & Philips & 0.338 & 0.0001 \\
\hline 1 & $\mathrm{~F}$ & Head of Household & 325 & Simple Random & GHQ-28 & Researcher & 0.259 & 0.0001 \\
\hline 33 & $\mathrm{M}$ & Student & 200 & Stratified & $\begin{array}{l}\text { SCL- } 90 \\
\end{array}$ & Najarian & 0.311 & 0.002 \\
\hline 34 & $\mathrm{M} \& \mathrm{~F}$ & Student college & 150 & Simple Random & GHQ-28 & Mixed & 0.369 & 0.0001 \\
\hline 35 & $\mathrm{~F}$ & Employee & 60 & Purposive & GHQ-28 & Heller & 0.330 & 0.01 \\
\hline 36 & $\mathrm{M}$ & Veteran & 210 & Stratified & GHQ-28 & Zimet & 0.310 & 0.0001 \\
\hline 37 & $\mathrm{M} \& \mathrm{~F}$ & Student college & 262 & Stratified & GHQ-28 & Fleming & 0.187 & 0.002 \\
\hline 38 & $\mathrm{~F}$ & MS Patient & 83 & Convenience & GHQ-28 & Zimet & 0.176 & 0.112 \\
\hline 39 & $\mathrm{~F}$ & Student college & 120 & Stratified & GHQ-12 & Philips & 0.440 & 0.0001 \\
\hline 40 & $\mathrm{M} \& \mathrm{~F}$ & Student college & 300 & Cluster & GHQ-28 & Philips & 0.220 & 0.0001 \\
\hline 41 & $\mathrm{M} \& \mathrm{~F}$ & Student college & 200 & Cluster & GHQ-28 & Pierce & 0.146 & 0.139 \\
\hline 42 & $\mathrm{M} \& \mathrm{~F}$ & Student college & 2776 & Census & GHQ-12 & Stanford & 0.255 & 0.0001 \\
\hline 43 & $\mathrm{M} \& \mathrm{~F}$ & Immigrant & 600 & Simple Random & SCL- 90 & Mixed & 0.510 & 0.0001 \\
\hline 44 & $\mathrm{M} \& \mathrm{~F}$ & Student college & 428 & Simple Random & GHQ-28 & Zimet & 0.370 & 0.0001 \\
\hline 45 & $\mathrm{~F}$ & Abused women & 412 & Convenience & GHQ-28 & Researcher & 0.100 & 0.177 \\
\hline 46 & $\mathrm{M} \& \mathrm{~F}$ & Employee & 149 & Census & GHQ-28 & Stanford & 0.262 & 0.0001 \\
\hline 47 & $\mathrm{M} \& \mathrm{~F}$ & Nurse & 380 & Clustered & GHQ- 12 & Philips & 0.401 & 0.0001 \\
\hline 10 & $\mathrm{M} \& \mathrm{~F}$ & Employee & 175 & Stratified & GHQ-28 & Rosenberg & 0.077 & 0.341 \\
\hline 48 & $\mathrm{M} \& \mathrm{~F}$ & AIDS Patient & 70 & convenience & GHQ-28 & Zimet & 0.330 & 0.005 \\
\hline 49 & $\mathrm{M} \& \mathrm{~F}$ & MS Patient & 120 & Simple Random & SF- 36 & Philips & 0.341 & 0.0001 \\
\hline 50 & $\mathrm{M} \& \mathrm{~F}$ & Nurse & 108 & Convenience & GHQ-28 & Philips & 0.210 & 0.004 \\
\hline 51 & $\mathrm{M} \& \mathrm{~F}$ & AIDS Patient & 120 & Simple Random & GHQ-28 & Philips & 0.110 & 0.232 \\
\hline 52 & $M \& F$ & Married workers & 400 & Cluster & SCL-90 & Heller & 0.614 & 0.0001 \\
\hline 53 & $\mathrm{M} \& \mathrm{~F}$ & Dialysis patient & 60 & Census & GHQ-28 & Heller & 0.430 & 0.001 \\
\hline 54 & $\mathrm{M} \& \mathrm{~F}$ & Public people & 384 & Cluster & GHQ-28 & Researcher & 0.352 & 0.0001 \\
\hline 55 & $\mathrm{M} \& \mathrm{~F}$ & Teacher & 250 & Simple Random & GHQ-28 & Zimet & 0.302 & 0.0001 \\
\hline 11 & $\mathrm{M} \& \mathrm{~F}$ & Elder & 200 & Convenience & GHQ-28 & Zimet & 0.066 & 0.354 \\
\hline 56 & $\mathrm{M} \& \mathrm{~F}$ & Student college & 2916 & Census & GHQ- 12 & Stanford & 0.560 & 0.0001 \\
\hline 57 & $\mathrm{M} \& \mathrm{~F}$ & blind and deaf children & 131 & Convenience & GHQ-28 & Sherbourne & 0.460 & 0.0001 \\
\hline 58 & $\mathrm{M} \& \mathrm{~F}$ & Student college & 320 & Cluster & $36-\mathrm{SF}$ & Najarian & 0.410 & 0.0001 \\
\hline 59 & $\mathrm{M} \& \mathrm{~F}$ & Diabetic patients & 50 & Convenience & WHO & Zimet & 0.520 & 0.0001 \\
\hline 60 & $\mathrm{M} \& \mathrm{~F}$ & Student college & 400 & Cluster & GHQ-28 & Heller & 0.350 & 0.0001 \\
\hline 61 & $\mathrm{M} \& \mathrm{~F}$ & Shahed Student colleges & 133 & Convenience & GHQ-28 & Heller & 0.378 & 0.0001 \\
\hline 62 & $\mathrm{M}$ & Teacher & 200 & Stratified & GHQ-28 & Sarason & 0.202 & 0.004 \\
\hline 63 & $\mathrm{M} \& \mathrm{~F}$ & Student college & 300 & Stratified & GHQ-28 & Researcher & 0.295 & 0.0001 \\
\hline 6 & $\mathrm{~F}$ & Mothers & 100 & Cluster & GHQ-28 & Zimet & 0.710 & 0.0001 \\
\hline 64 & $\mathrm{~F}$ & Student & 351 & Cluster & GHQ- 12 & Philips & 0.260 & 0.0001 \\
\hline
\end{tabular}




\begin{tabular}{|l|l|l|l|l|l|l|l|l|}
\hline 65 & $\mathrm{M}$ & Employee & 267 & Convenience & SCL- 90 & Philips & 0.177 & 0.004 \\
\hline 66 & $\mathrm{M} \& \mathrm{~F}$ & Public people & 877 & Simple Random & GHQ-28 & Researcher & 0.191 & 0.0001 \\
\hline 67 & $\mathrm{M} \& \mathrm{~F}$ & Elder & 160 & Convenience & Researcher & Researcher & 0.146 & 0.066 \\
\hline 68 & $\mathrm{~F}$ & Student & 500 & Cluster & 36 -SF & Zimet & 0.298 & 0.0001 \\
\hline 69 & $\mathrm{M} \& \mathrm{~F}$ & Transsexual & 97 & Convenience & GHQ-28 & Zimet & 0.532 & 0.0001 \\
\hline 70 & $\mathrm{M} \& \mathrm{~F}$ & Diabetic patients & 120 & Simple Random & SCL- 90 & Sameni & 0.280 & 0.002 \\
\hline 71 & $\mathrm{M} \& \mathrm{~F}$ & Student college & 392 & Cluster & GHQ-28 & Zimet & 0.280 & 0.0001 \\
\hline 72 & $\mathrm{M} \& \mathrm{~F}$ & Elder & 356 & Cluster & GHQ-28 & Berkman & 0.357 & 0.0001 \\
\hline 73 & $\mathrm{M} \& \mathrm{~F}$ & Infertile couples & 130 & Convenience & GHQ-28 & Zimet & 0.140 & 0.112 \\
\hline 74 & $\mathrm{M} \& \mathrm{~F}$ & Disabled children & 284 & Convenience & MHC & Zimet & 0.377 & 0.0001 \\
\hline 75 & $\mathrm{M} \& \mathrm{~F}$ & Public people & 271 & Stratified & GHQ-28 & Katrona & 0.613 & 0.0001 \\
\hline 76 & $\mathrm{~F}$ & Infertile Women & 95 & Convenience & MHI & Zimet & 0.440 & 0.0001 \\
\hline 77 & $\mathrm{M} \& \mathrm{~F}$ & Elder & 180 & Cluster & 36-SF & Zimet & 0.222 & 0.003 \\
\hline
\end{tabular}

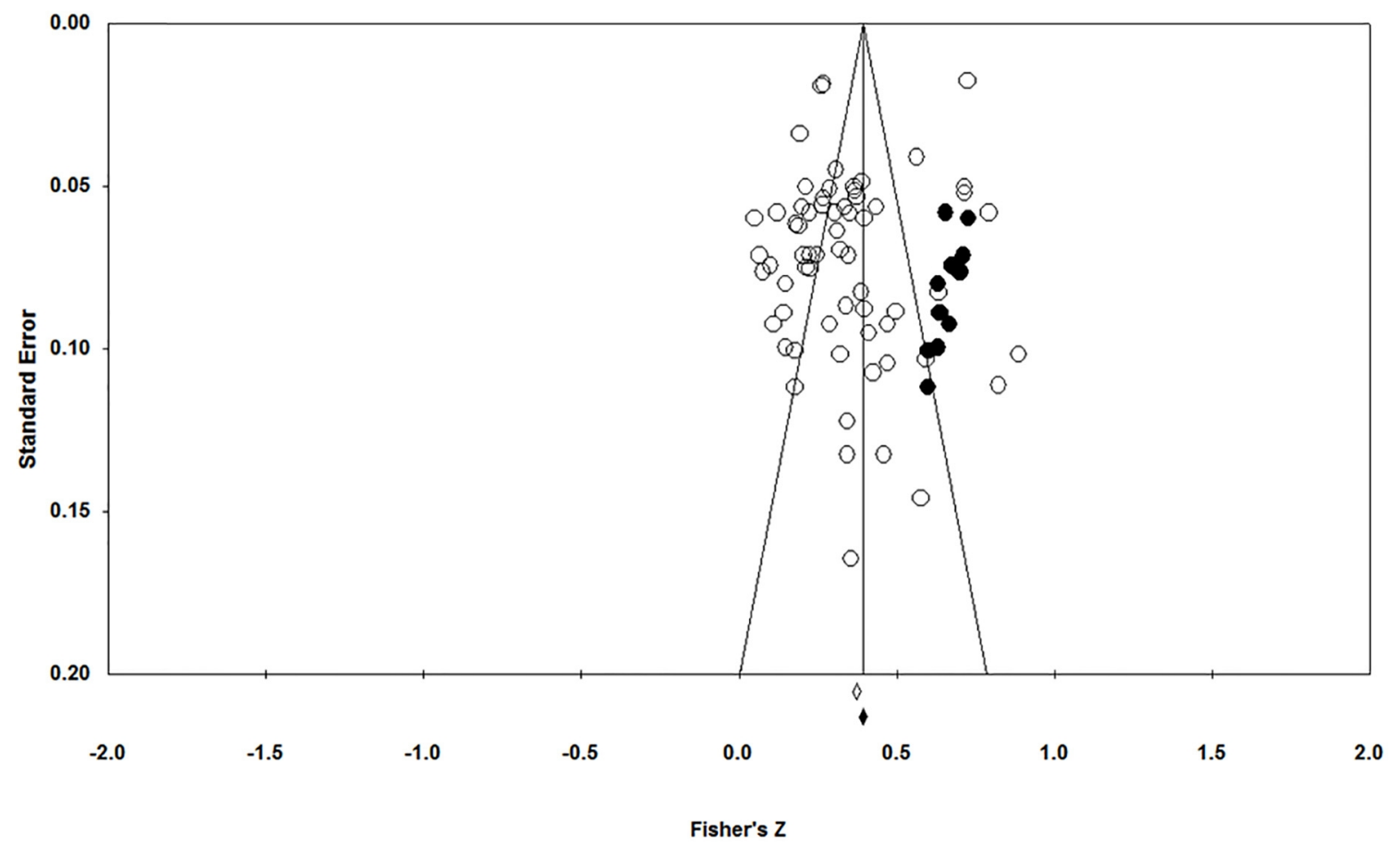

Figure 2. Funnel plot

According to Table 2, the Z statistic showed a significant difference between different classes of the variables (the sex, target population, sampling method, and instruments for measurement of social support and mental health) in terms of the effect size. The results showed that the studies on females (0.372) had higher effect size than the studies on males (0.341). This result indicated the higher correlation of social support on females' mental health. The analysis of the target population of the studies revealed the high effect of social support on mental health in parents with disabled children, immigrants, and people seeking to change their sex; the effect size of social support on mental health in university students, ordinary people, workers, and veterans was higher than the average level; and the effect size of social support on mental health in female heads of household, infertile couples, school students, women who had been abused, and older adults, was at the average level. In respect of the sampling method, the studies that had used census method comprised maximum effect size (0.373) because they had measured the entire statistical population; and the studies that had used simple random sampling, reported minimum effect size (0.283). The studies with other sampling methods had the effect size higher than the average level. Furthermore, the study that had used the mental health subscale of the World Health Organization's quality of life questionnaire showed the maximum effect size, and the study that had used GHQ-28 showed the minimum effect size. It is noteworthy that all effect sizes were higher than average. Regarding the moderator variable, the social support questionnaire and the studies that had used questionnaires developed by Katrona \& Russell, Sherbourne and Stewart, Procidano and 
Heller, Najarian, Rook \& Ituarte, Phillips, and Zimet; and the subscale of social capital questionnaire, had the effect size higher than the average level. The studies that had used questionnaires developed by Rosenberg, Pierce, and Fleming to measure the perceived social support, had a small effect size. Considering that the significance level of the Q statistic for sex, sampling method, and mental health questionnaire was greater than 0.05 , it could be argued that these variables are not moderators of the correlation between social support and mental health. As shown in Table 2, however, the Q statistic for the target population and social support questionnaire was significant at 0.05 . Therefore, it could be argued by $95 \%$ confidence that the target population and social support questionnaire contributed to the heterogeneity, and were thus considered as moderator variables in the correlation between social support and mental health.

Table 2. Examining the moderator variables of the correlation between social support and mental health

\begin{tabular}{|c|c|c|c|c|c|}
\hline \multicolumn{2}{|l|}{ Moderator } & \multirow{2}{*}{\multicolumn{4}{|c|}{ Indicators }} \\
\hline & & & & & \\
\hline \multirow{3}{*}{ Gender } & Male \& Female & $\begin{array}{l}\text { No. of } \\
\text { Studies } \\
47\end{array}$ & $\begin{array}{l}\text { Effect size } \\
0.318\end{array}$ & \multirow{3}{*}{$\begin{array}{l}\begin{array}{l}\text { Z-value } \\
\text { (p-value) }\end{array} \\
12.712 \\
(0.0001)\end{array}$} & \multirow{3}{*}{$\begin{array}{l}\begin{array}{l}\text { Q-value } \\
\text { (p-value) }\end{array} \\
0.857 \\
(0.6)\end{array}$} \\
\hline & Female & 12 & 0.372 & & \\
\hline & Male & 5 & 0.341 & & \\
\hline \multirow[t]{13}{*}{ Target population } & Student college & 18 & 0.337 & \multirow{13}{*}{$\begin{array}{l}21.265 \\
(0.0001)\end{array}$} & \multirow{13}{*}{$\begin{array}{l}46.661 \\
(0.0001)\end{array}$} \\
\hline & Employee & 12 & 0.321 & & \\
\hline & Elder & 9 & 0.257 & & \\
\hline & Patient & 7 & 0.296 & & \\
\hline & Student & 4 & 0.274 & & \\
\hline & Public people & 3 & 0.399 & & \\
\hline & Parents of disabled children & 3 & 0.526 & & \\
\hline & Abused women & 2 & 0.245 & & \\
\hline & Infertile couples & 2 & 0.293 & & \\
\hline & Female-headed households & 1 & 0.259 & & \\
\hline & Veteran & 1 & 0.31 & & \\
\hline & Immigrant & 1 & 0.51 & & \\
\hline & Seeking sex change & 1 & 0.531 & & \\
\hline \multirow[t]{6}{*}{ Sampling } & Clustered & 19 & 0.317 & \multirow{6}{*}{$\begin{array}{l}1.558 \\
(0.0001)\end{array}$} & \multirow{6}{*}{$\begin{array}{l}2.126 \\
(0.831)\end{array}$} \\
\hline & Stratified & 12 & 0.361 & & \\
\hline & Simple random sampling & 9 & 0.283 & & \\
\hline & Convenience & 16 & 0.322 & & \\
\hline & Census & 7 & 0.373 & & \\
\hline & Purposive sampling & 1 & 0.330 & & \\
\hline \multirow{7}{*}{$\begin{array}{l}\text { Questionnaires of general } \\
\text { health }\end{array}$} & GHQ-12 & 14 & 0.362 & \multirow{7}{*}{$\begin{array}{l}932.18 \\
(0.0001)\end{array}$} & \multirow{7}{*}{$\begin{array}{l}574.12 \\
(0.083)\end{array}$} \\
\hline & GHQ -28 & 35 & 0.306 & & \\
\hline & SCL- 90 & 7 & 0.346 & & \\
\hline & SF-36 & 4 & 0.353 & & \\
\hline & WHO & 1 & 0.52 & & \\
\hline & MHI & 1 & 0.44 & & \\
\hline & $\mathrm{MHC}$ & 1 & 0.377 & & \\
\hline \multirow{14}{*}{$\begin{array}{l}\text { Questionnaires of social } \\
\text { support }\end{array}$} & Zimet & 17 & 0.322 & \multirow{14}{*}{$\begin{array}{l}19.148 \\
(0.0001)\end{array}$} & \multirow{14}{*}{$\begin{array}{l}42.8 \\
(0.0001)\end{array}$} \\
\hline & Philips & 11 & 0.315 & & \\
\hline & Stanford & 5 & 0.428 & & \\
\hline & Najarian & 3 & 0.355 & & \\
\hline & Procidano, Heller & 5 & 0.434 & & \\
\hline & Najarian & 2 & 0.387 & & \\
\hline & Katrona \& Russell & 2 & 0.481 & & \\
\hline & Rook \& Ituarte & 1 & 0.333 & & \\
\hline & Sarason & 1 & 0.235 & & \\
\hline & Rosenberg & 1 & 0.076 & & \\
\hline & Sherbourne \& Stewart & 1 & 0.465 & & \\
\hline & Pierce & 1 & 0.146 & & \\
\hline & Fleming & 1 & 0.187 & & \\
\hline & Researcher made & 7 & 0.215 & & \\
\hline
\end{tabular}




\section{Discussion}

The mean of effect size of studies in the fixed-effect model and random-effect model was obtained respectively as 0.356 and 0.330 , both of which are significant at 0.001, and are considered average, based on Cohen criteria (19). These results are aligned with other studies' results $(14,16,17)$. So it can be said that positive social communication with family members and friends reduces anxiety and develops the feeling of security. People with more positive ethnical social relations and higher social support enjoy more efficient communication skills, which directs them away from depression and other mental problems (34). Moreover, Cobb introduces the social support as a protector against stress in a way that it largely affects social health and performance. Cobb explains that social support gives people the feeling of being loved, cared, respected, and belonging to a network of communication (78). According to Durkheim's theory, people do not receive social support and their health is at risk if social unity is poor. Conversely, a high level of social support protects people from illnesses (7). Also, the results revealed that sex, sampling method and a mental health questionnaire did not moderate in the correlation between social support and mental health but the target population and social support questionnaire doesn't have the role of mediator. The results showed that studies that have been conducted solely on women, had higher effect size than the studies on men. These results are aligned with other studies' results $(79,80,25)$. In this respect, the effect size of social support varies with sex in a way that women discuss their emotional problems with others outside the family, more than men do. It may be more difficult for men to accept their anxieties, fears, and depressions due to the social perceptions expected from men regarding their gender role behaviors. Men's inability to cope with stresses may be deemed their weakness, and thus, they may not use the support from helping contexts because they are afraid of losing their dignity and status (2). In this study the effect size of social support on mental health was examined and compared in the different groups. Results revealed the high correlation of social support with mental health in parents with disabled children, immigrants, and people seeking to change their sex; the effect size of social support on mental health in university students, ordinary people, workers, and veterans was higher than the average level; and the effect size of social support on mental health in female heads of household, infertile couples, school students, women who had been abused, and older adults was at the average level. According to Rathus, social support reduces the adverse effects of mental stress in 5 ways: emotional attention, helping, information, assessment of others' feedback about the quality of performance, and sociability (20). University students and workers who access social networks more than others are more likely to contact social support networks and be more skilled in receiving social support when they experience stressful situations or have problems. Furthermore, immigrants with higher social, mental, and financial support; kinship networks; sense of belonging and attachment; and participation in various aspects of social life in new environments enjoy better mental health in that new society (43). Parents who have disabled children but receive social support, are capable of giving meaning to life problems, mental stresses, physical disabilities, and the psychological vulnerability and consequently, reducing mental pressure (57). In older adult communities, it should be said that older people who receive more social support and participate in different aspects of social life more than others, enjoy more favorable mental health. Perceived social support can inhibit the adverse physiological complications of diseases and increase self-care among older people (31). In the field of social support on patients' mental health, patientscertainly find themselves in a precarious situation and look for support that decreases their anxiety and discomfort, and thus, social support in such a situation can reduce their anxiety and discomfort (25). The results showed that the studies that had used census method showed maximum effect size, because this method investigates the entire study population and consequently, is more accurate.

\section{Conclusions}

Regarding the significant correlation of social support on mental health, the relevant authorities are recommended to hold seminars for the families of school students, university students, workers, older adults, and vulnerable groups, and offer training brochures to them in order to make them aware of their irreplaceable support, emphasize the persistency of family relations, and provide them with practical strategies for improving relations. Counseling centers can teach practical strategies for receiving social support through holding training workshops in order to improve their mental health, and prevent the incidence of psychological problems and other behavioral disorders and emotional inconsistencies. Researchers are recommended to pay more attention to the relationship between social support and mental health in special and damaged groups. Furthermore, researchers are suggested to use measurement instruments with high reliability and validity regarding the influence of the type of questionnaire on the effect size of the studies.

\section{Acknowledgments:}

We thank the Social Determinants of Health Research Center, Alborz University of Medical Sciences who supported this research. 


\section{Conflict of Interest:}

There is no conflict of interest to be declared.

\section{Authors' contributions:}

All authors contributed to this project and article equally. All authors read and approved the final manuscript.

\section{References:}

1) Garousi, S, Shabestari SH. Social Capital and Mental Health among Household Head Women Surveying the Relationship in the City of Kerman. Iranian Social Studies. 2012; 5(1): 1-123.

2) Cokrin R. social basics of mental deseases. Translated by Bahman Najarian. Tehran: Roshd publication; 1997.

3) Marmot M, Wilkinson R. Social Determinants of health. Translated by Ali Montazeri. Tehran: Iranian Institute for Health Sciences Research; 2008.

4) Morovati Sharifabad MA, Rohani Tonekaboni N. Social support and self-care behaviors in diabetic patients referring to Yazd Diabetes Research Center; 2008.

5) Brummett BH, Mark DB, Siegler IC, Williams RB, Babyak MA, Clapp-Channing NE, et al. Perceived social support as a predictor of mortality in coronary patients: effects of smoking, sedentary behavior, and depressive symptoms. Psychosom Med. 2005; 67(1): 40-5. doi: 10.1097/01.psy.0000149257.74854.b7. PMID: 15673622 .

6) Afrooz Q, Taghizadeh H. Comparison of Perceived Social Support and Mental Health of Mothers of Children with and without Hearing. Exceptional Education. 2014; 2(124): 7-17.

7) Kamran F, Ershadi Kh. discovering social capital and mental health relationship. Pojohesh Ejtemaee. 2000; 2(3): 29-54.

8) Shakerinia I. Effect of Social Assists and Hopefulness in Elderly Health Status with Chronic Pain Salmand. 2012; 7(1): 7-15.

9) Pahlevanzadeh $\mathrm{F}$, Jarelahi O. Investigating the effect of social factors on mental health of rural elders. Journal of Rural development. 2011; 3(1): 65-84.

10) Mirbagheri R MirJaefari A, Nissi AK. Relationship between job stress and Organizational climate with mental health, according to a moderating variable of perceived social support organizational in staff of four areas of Shiraz education. in psychology. Shiraz Azad University. 2009.

11) Rajai M, Aflakseyr AA, Mollazadeh J. Predict of mental health in the elderly over 65 years old based on the Mac Kynlay spiritual model. Shiraz: Shiraz University; 2012.

12) Delavar A. The theoretical and practical bases of research in human and social sciences. Tehran: Roshd Pub; 2011.

13) Kulik JA, Kulik CLC. The concept of meta-analysis. International Journal of educational research. 1989; 13(3): 227-340. doi: 10.1016/0883-0355(89)90052-9.

14) Schwarzer R, Leppin A. Social support and health: A meta-analysis. Psychology and health. 1989; 3(1): 115. doi: $10.1080 / 08870448908400361$.

15) De Silva MJ, McKenzie K, Harpham T, Huttly SR. Social capital and mental illness: a systematic review. J Epidemiol Community Health. 2005; 59(8): 619-27. doi: 10.1136/jech.2004.029678. PMID: 16020636, PMCID: PMC1733100.

16) Wang HH. A meta-analysis of the relationship between social support and well-being. Kaohsiung J Med Sci. 1998; 14(11): 717-26. PMID: 9838768.

17) DiMatteo MR. Social support and patient adherence to medical treatment: a meta-analysis. Health Psychol. 2004; 23(2): 207-18.

18) Moradi AT, Javanbakht F, Taheri. A meta-analysis on the relationship between mental health and social support in Iran. Behavioral Sciences. 2013; 10(6): 565-73.

19) Cohen J. A power primer. Psychol bull. 19912; 112(1); 155-9. doi: 10.1037/0033-2909.112.1.155. PMID: 19565683.

20) Bakhshi Pour Roudsari A, Peyravi H, Abedian A. Investigating relationship between satisfaction with life and social support with mental health among freshman students of Tehran University. Fundamentals of Mental Helth. 2005; 7(3): 145-52.

21) Seifzadeh, A. The relationship between perceived social support and health in elder, Case study: Azarshahr. 2016; 1(1): 40-47. 
22) Motamedi Shalamzari, A. Agee,J. Azadfallah, P. Kiamanesh, A. The study of the role of social support in life satisfaction, general health and loneliness among elderly over 60 years of age. Journal of Psychology. 2001; 6(2): 115-133.

23) Kamran,F. Ershadi, Kh. Study of the relationship between social capital of the network and mental health. Journal of Social Research. 2009; 2(3): 29-54.

24) Mohseni Tabrizi, A.1 .Razi, A. Social Support for Mental Health of Tehran University Students. social Sciences. 2007; 10,11: 83-96.

25) Riahi MA. Verdinia AA, Pourhossein Z. Relationship between social support and mental health. Social Welfare. 2011; 10(39): 85-121.

26) Hossein Zadeh, A.H . Bahraminejad, Z. Faroutan Kia, Sh. The Effect of Social-Emotional Support and Strong Relationship On General Health (Case Study: Male Students Boarding school Sardasht District, Dezful). Social Sciences (Shoushtar Azad University). 2012; 6(17): 143-164.

27) Hessam, M. Asayesh, H. Ghorbani, M. Shariati, A. R Nasiri, H. Relationship between Perceived Social Support, Mental Health and Life Satisfaction in college Students. Journal of Nursing and Midwifery, Gorgan, 2001; 8 (1): 41-34.

28) Hosseini, A. Dodeman Firuz Salari, S. The role of social support in the mental health of young employeesTehran municipality. Social welfare planning and development. 2010; 3(1): 111-114.

29) Pennaghi, L. Ghahari, Sh. Ahmad Abadi, Z. Yousefi, H. Spouse abuse and mental health: the role of social support and coping strategies. Evolutionary Psychology (Iranian Psychologists). 2008; 5,17: 69-79.

30) Sydan, F. Abdul Samadi, M. The relationship between social capital and mental health of women and men. Social welfare. 2011; 11(2): 229 - 254.

31) Shoja M, Rimaz Sh, Asadi-Lari M, Bagheri Yazdi A, Gohari MR. Evaluation of mental health and its relationship with social capital seniors. Journal of monitoring. 2013; 12(4): 345-53.

32) Azadi, S. Azad, H. Investigating the relationship between social support, resiliency and mental health of witnessed and selfless students in Ilam universities. Veterans Medicine. 2011; 3(4): 48-58.

33) Nisi, A.K. Najarian, B. Pourfarj, S.F. Comparison of academic performance, physical and mental health of male and female non-fathered children due to the role of moderating social support in first grade high schools in Ahvaz. Journal of Educational Sciences and Psychology. 2001; 8(3,4): 67-86.

34) Ghasemipoor M, Jahanbakhsh Ganjeh S. The relationship between the social support and mental health in Lorestan university students. Yafteh. 2010; 12(1): 57-64.

35) Hamidi, F. The study of the relationship between social support and mental health in female headed households in a military university staff. Military Psychology. 2010; 1(2): 51-60.

36) Soltani, M. Ahmadi, T., Karaminia, R., \& Hashemian, S. A. Prediction of war veteran's mental health based on spiritual well-being, social support and self-efficacy variables: The mediating role of life satisfaction. Journal of education and health promotion, 2014; 3.

37) Tajalli, P., \& Ganbaripanah, A. The relationship between daily hassles and social support on mental health of university students. Procedia-Social and Behavioral Sciences. 2010; 5: 99-103.

38) Alipour, A. Sahraeian, M.A. Ali Akbari, M. Haji Agha Baba'I, M. Relationship between perceived social support and hardiness with mental health and disability status in women with multiple sclerosis. Social Psychology Research. 2011; 1(3): 110-133.

39) Pouragharoudfaradeh, F. Kafi, S.M. Rezaei, S. Relationship between feeling alert and perceived social support with mental health of newly arrived students. Clinical Psychology and Personality (Daneshvar Behavior). 2012; 19(6): 27-36.

40) Mirsamei, M. Ebrahimi Ghavamabadi, S. The study of the relationship between self-efficacy, social support and test anxiety with mental health of female and male students of Allameh Tabataba'i University. Educational Psychology (Psychology and Educational Sciences). 2007; 2(7): 73-91.

41) Vessey, M. Atef Vahid, M.K. Rezaei, M. The Effect of Job Stress on Job Satisfaction and Mental Health: Moderating Impact of Hardiness and Social Protection. Psychiatry and Clinical Psychology of Iran. 2000; 6(2,3): 70-79.

42) Peyravi, H. Abedian, A. Mental health and social support. New psychotherapy. 2007; 12(1,2): 67-86.

43) Lhsayi zade, A. Moradi, G.M. The relationship between social capital and mental health in immigrants. Social Welfare. 2007; 7(2):161-180.

44) Jamali, M. Norouzi, A.Tahmasbi, R. Application of the Basic Structures of Social Cognition Theory in predicting mental health of students of Bushehr University of Medical Sciences in 2012-2013. South medicine. 2013; 7(6): 1251-1236. 
45) Khaghani Fard, M. Investigating the role of violence against women, gender socialization and social capital in predicting mental health of a group of women in Tehran. Socio-Psychological Studies of Women (Women Studies). 2011; 9(2): 55-80.

46) Hajibi, A. Fereidnia, P. The relationship between mental health and social support in health staffs of Bushehr oil industry. South medicine. 2009; 12(1): 67-74.

47) Mohabi, Sh. Investigating the relationship between attachment styles and social support and its impact on mental health. Islamic Azad University, Central Tehran. Faculty of Education and Psychology, MSc. 2011.

48) Hatfi nia, M. The study of the relationship between social support and general health of patients with HIV (AIDS) and its comparison with normal Farad in Shiraz. Allameh Tabatabaei University, Faculty of Psychology, MSc. 2011.

49) Charkhian, A. The study of the relationship between social support and quality of life in people with HIV who referred to Imam Khomeini Hospital in Tehran. University of Social Welfare and Rehabilitation Sciences, MSc. 2009.

50) Memarbashy, M. Comparison of the relationship between social support and stress coping strategies with job performance and mental health in nursing staff in psychiatric and non psychiatric hospitals. Mashhad Ferdowsi University, MSc. 2011.

51) Hosseini S.M.D. Mollazadeh, J, Afsarkhazaroni, P. Amini Lari, M. Relationship between attachment styles and coping styles with mental health in HIV + patients. Principles of Mental Health. 2012; 14(1): 6-15.

52) Vahdani, F. Investigation of Sociological and Psychological Factors Affecting Mental Health of Married Women Employed (Case Study: Ghorveh City). University of Isfahan, Faculty of Literature and Human Sciences, MSc. 2010.

53) Rabbani Jahromi, F. The Relationship between Social Support and Religious Beliefs with Mental Health in Dialysis Patients in Jahrom City. Islamic Azad University, Marvdasht, Faculty of Education and Psychology, MSc. 2011.

54) Mobarak Bakhshayesh, M. Investigating the Impact of Social Capital on the Health of Citizens of Isfahan. University of Isfahan, Faculty of Literature and Human Sciences, MSc. 2010.

55) Heydari, M. Psychological social anxiety mental health among high school teachers in Jiroft city. University of Yazd, Faculty of Literature and Human Sciences, MSc. 2010.

56) Peyravi, H. Hajabi, A. Pnaghi, L. The Relationship between Social Support and Mental Health in Tehran University Students. Health system research. 2010; 6(2): 301-307.

57) Bahri L. Dehghan Menshadi M, Dehghan Manshadi Z. Investigate the predictive role of resilience and social support on the mental health of parents of blind children and deaf. Exceptional education. 2014; 14(1): 5-12.

58) Fooladvand, Kh. Farzad, V. Shahari, M. Sangari, A.A. The effect of social support, academic stress and academic self-efficacy on mental and physical health. Contemporary psychology. 2009; 4(2): 81-93.

59) Share, H. Soltani, E. Ghasemi, A. Prediction of Quality of Life of Non-Insulin-Dependent Diabetic Patients Based on Perceived Social Support. ZJRMS. 2012; 14 (2):82-85

60) Moghry, M. Bigonah, M. The study of the relationship between social support and mental health of students. Conference families, students, university. 2009.

61) Sheikh Ali Zadeh, S. Ahmadi, E.A. Investigating the Impact of Family Social Support And friends On the mental health of witnesses and non-university students of Azarbaijan Teacher Training University. Family, student and university congress. 2009.

62) Arefi, M. Asgari, S. Hani, S. Attachment style, social support and psychological health in youth and adults. Psychological Health Conference. 2009.

63) Mazhabdar, H. Hoseini, M. Zahediasl, M. Investigating the Social factors associated with the mental health of the Faculty of Social Sciences students of Allameh Tabatabai University in 2010-2011. psj. 2014; 12 (2) $: 55-63$

64) Yavarinia, S. Sepehrian, F. Yousefi, R. (2014). Investigating the role of control feeling, social support and general health in test anxiety in third grade high school students in Uromie. School Psychology. 2014; 3(4): 143-156.

65) Motvryan, M. The relationship between social support and psychological hardiness with mental health shift workers and day workers of Karoun Oil and Gas. Islamic Azad University of Marvdasht, Faculty of Education and Psychology, MSc. 2012.

66) Mardani Rad, M. Delavar, A. Alipour,A.Saffarinia, M. (2014). Social support, mental health, quality and life satisfaction: a structural model. Psychological Researches. 2014; 6(4): 35-42. 
67) Navabinejad, Sh. Dowkanehee, F. Shirzadi, Sh. The effect of family factors affecting mental health of elderly women and men in district 13 of Tehran municipality. Educational Management Research. 2013; 5(1): 119-132.

68) Shakib, Z. Tahmasbi, R. Nowroozi, A. (2014). Factors Affecting Mental Health of High School Girls in Bushehr City Based on Social Cognition Theory (Student's Mental Health). Health Education and Health Promotion of Iran. 2014; 2(2): 131-142.

69) Gharaat, M. Mohammadi, A. Association between perceived social support and mental health among Transsexuals. Social work. 2014; 3(2): 19-32.

70) Atadokht A, Narimani M, Ahadi B, Abolghasemi A, Zahed A, Iranparvar M. (2013). Study of the Psychological Profile in Diabetic Patient and its Relationship with their Social Support. J Ardabil Univ Med Sci. 2013; 13 (2):195-205.

71) Ghasemi, A. Arianpour, S. The relationship between social support and cultural convergence with students' mental health and illumination. Social Science. 2011; 5(1): 125-149.

72) Hosseini, H. Bahraminejad, Z. The Role of Social Support Networks in Public Health and Utilization of Health Services among the Elderly. Research and Health. 2014; 4(4): 95-961.

73) Hasanpour, S., Bani, S., Mirghafourvand, M., \& Kochaksarayie, F. Y. Mental health and its personal and social predictors in infertile women. Journal of caring sciences. 2014; 3(1): 37.

74) Entezar, R.K., \& Rad, M.M. The Relation between Emotional Intelligence, Social Support and Mental Health among Iranian and Malaysian Mothers of Mild Intellectually Disabled Children. 2014.

75) Navah, A., Koopaei, M. B., \& Rezapour, D. Study of Factors Affecting Mental Health Status of Young People Aged Over 18 Years Old Living in Ahvaz City, Iran. IAU International Journal of Social Sciences. 2013; 3(4): 43-48.

76) Mousavi, S. Najafi Kalyani, M. Karimi, Sh. Kokabi, R. Piriaee, S. The Relationship between Social Support and Mental Health in Infertile Women: The Mediating Role of Problem-focused Coping. Scholars Journal of Applied Medical Sciences (SJAMS). 2015; 3(1): 244-248.

77) Harouni, M. Hosseini, M. Majd, H.A. Yaghmaie, F. Montazeri, A., Barzegar, H.H.G. \& Ibrahim, A. A. (2013). Social support and health-related quality of life among older adults: a descriptive study. Report and Opinion. 2013; 5(12): 1-6.

78) Cobb S. Social support as a moderator of life stress. Psychosom med. 1976; 38(5): 300-14. doi: 10.1097/00006842-197609000-00003. PMID: 981490.

79) Landman-Peeters KM, Hartman CA, van der Pompe G, den Boer JA, Minderaa RB, Ormel J. Gender differences in the relation between social support, problems in parent-offspring communication, and depression and anxiety. Soc Sci Med. 2005; 60(11): 2549-59. doi: 10.1016/j.socscimed.2004.10.024. PMID: 15814180.

80) Ghaedi GH, Yaghoubi H. A study on the relationship between different dimensions of perceived social support and different aspects of wellbeing in male and female university students. Bringing Knowledge. 2008; 13(2): 69-81. 